Nowadays, artificial intelligence has entered into all spheres of human activity. However, there are some problems in the analysis of objects, for example, there is a priori uncertainty about the state of objects and the analysis takes place in a difficult situation against the background of intentional (natural) interference and uncertainty. The best solution in this situation is to integrate with the data analysis of information systems and artificial neural networks. This paper develops an improved method for finding solutions for neuro-fuzzy expert systems. The proposed method allows increasing the efficiency and reliability of making decisions about the state of the object. Increased efficiency is achieved through the use of evolving neuro-fuzzy artificial neural networks, as well as an improved procedure for their training. Training of evolving neuro-fuzzy artificial neural networks is due to learning their architecture, synaptic weights, type and parameters of the membership function, as well as the application of the procedure of reducing the dimensionality of the feature space. The analysis of objects also takes into account the degree of uncertainty about their condition. In the proposed method, when searching for a soluculated once, which speeds up the rule revision cycle and instead of the same conditions of the rules, references to them are used. This reduces the computational complexity of decision-making and does not accumulate errors in the training of artificial neural networks as a result of processing the information coming to the input of artificial neural networks. The use of the proposed method was tested on the example of assessing the state of the radio-electronic environment. This example showed an increase in the efficiency of assessment at the level of 20-25\% by the efficiency of information processing

Keywords: artificial intelligence, radio-electronic environment, intelligent systems, decision support systems tion, the same conditions are cal-

\section{DEVELOPMENT OF AN IMPROVED METHOD FOR FINDING A SOLUTION FOR NEURO-FUZZY EXPERT SYSTEMS}

0. Salnikova

Doctor of Public Administration Sciences, Senior Researcher, Head of Educational and Research Center*

O. Cherviakova

Doctor of Public Administration Sciences, Associate Professor, Vice-Rector for Scientific Work East European Slavic University Gagarina str., 42-1, Uzhhorod, Ukraine, 88018

O. Sova

Doctor of Technical Sciences, Head of Department Department of Automated Control Systems**

R. Zhyvotovsky i

$\mathrm{PhD}$, Senior Researcher, Head of Research Department $* * *$

S. Petruk

PhD, Deputy Chief of Research Department***

T. Hursk y i

$\mathrm{PhD}$, Associate Professor**

A. Shyshat skyi

$\mathrm{PhD}$, Senior Researcher

Research Department of Electronic Warfare Development Central Scientifically-Research Institute of Arming and Military Equipment of the Armed Forces of Ukraine Povitroflotskyi ave., 28, Kyiv, Ukraine, 03168 E-mail: ierikon13@gmail.com

A. Nos

$\mathrm{PhD}$

Department of Physics and Radio Electronics Ivan Kozhedub Kharkiv National Air Force University

Sumska st., $77 / 79$, Kharkiv, Ukraine, 61023

Ye. Neroznak Adjunct

Department of Automated Control Systems**

I. Prosh ch y n Lecturer

Department of Strategic Communications* *Educational and Research Center of Strategic Communications in the sphere of National Security and Defense Ivan Chernyakhovsky National Defense University of Ukraine

Povitrofloski ave., 28, Kyiv, Ukraine, 03049 **Military Institute of Telecommunication and Information Technologies named after the Heroes of Kruty

Moskovska str., 45/1, Kyiv, Ukraine, 01011 $* * *$ Research Department of the Development of Anti-Aircraft Missile Systems and Complexes Central Scientifically-Research Institute of Arming and Military Equipment of the Armed Forces of Ukraine Povitroflotskyi ave., 28, Kyiv, Ukraine, 03049

Copyright (C) 2020, O. Salnikova, O. Cherviakova, O. Sova,
Hurskyi, A. Shyshatskyi, A. Nos, Ye. Neroznak, I. Proshchyn R. Zhyvotovskyi, S. Petruk, T. Hurskyi, A. Shyshatskyi, A. Nos, Ye. Neroznak, I. Proshchyn
pen access article under the CC BY license (http://creativecommons.org/licenses/by/4.0)

\section{Introduction}

Nowadays, many areas of human activity use artificial intelligence approaches to solve important practical problems.
Expert systems have been successfully used in complex technical systems to solve informal or poorly formalized tasks, such as training, diagnostics, forecasting, control and measurement $[1,2]$. 
This class of intelligent information systems is characterized by the fact that they are able to model the thinking process of an expert when making a decision and explain why this or that result was obtained. This is achieved by implementing the procedure of logical inference on formalized knowledge about the subject area, about the processes that take place in it, about the laws that govern these processes [3, 5, 7].

However, there are some difficulties and problems in objects analyzing:

1) the analysis takes place against the background of intentional and natural disturbances;

2) the interpretation of the obtained results depends on the experience of the decision-maker and the completeness of additional information on a specific task (conditions of uncertainty);

3) high dynamics of changes in the state of the object and the environment;

4) a large number of features that characterize the object and the environment;

5 ) limited time for analysis and decision-making in conditions of uncertainty.

The best solution in this situation is to integrate the data analysis and artificial neural networks (ANN).

These circumstances lead to recourse to the theory of expert systems, where one of the important limitations in their use is the difficulty of formulating rules for machining. In this form, an effective methodology for recording, storing and using expert knowledge in the expert system for the operational sampling of knowledge should be developed [4].

An alternative method of capturing expertise without using rules consists in using artificial neural networks, using their ability to generalization, self-learning and retraining. Their advantages are also the ability to work in real time and quick adaptation to specific situations $[8,9]$.

These circumstances cause uncertainty in the conditions of the task of signal recognition and fuzzy statements in their interpretation, when the additional information may be incomplete and operators make decisions based on their experience.

Given the above, an urgent scientific task consists in developing an improved method for finding solutions for neuro-fuzzy expert systems, with the following properties:

- able to operate in conditions of uncertainty;

- able to operate in conditions of incomplete information;

- able to conduct training of the architecture and parameters of ANN.

\section{Literature review and problem statement}

In [10], it is proposed to use neuro- fuzzy systems to predict the efficiency of building structures. This approach allows predicting the efficiency of building structures in conditions of probabilistic and improbable uncertainty. The disadvantages of this approach include the inability to learn the architecture and parameters of the artificial neural network, as well as the accumulation of errors during the operation of the system. This does not allow obtaining reliable results after 5-10 iterations of the approach.

In [11], it is proposed to use fuzzy expert systems for estimating the creative abilities of a person. This approach is based on the use of fuzzy logic to assess the creative abilities of a person in the selection of personnel. The disadvantages of this approach include the accumulation of errors during the procedures of fuzzification and defuzzification. Also, this approach does not take into account the type of uncertainty. This does not allow assessing the adequacy of the obtained decisions.

In [12], it is proposed to use fuzzy expert systems for forecasting the loading on electric networks. The genetic algorithm and the ant colony algorithm are used to speed up the decision. The disadvantages of this approach include the accumulation of errors in the procedures of fuzzification and defuzzification, as well as there is no reduction in the dimensionality of the feature space. Also, this approach does not take into account the type of uncertainty. This does not allow assessing the adequacy of the obtained decisions.

The paper [13] proposes an intelligent evaluation methodology based on fuzzy logic and expert systems. The principle of this methodology is to transform abstract concepts of human expertise into a numerical engine of inference that is applied to evaluation. Therefore, it reproduces the cognitive mechanisms of evaluation experts. An example of implementation is given to compare this method with the classical one and draw conclusions about its effectiveness. In addition, due to its flexibility, various types of extensions are possible by updating the basic rules and adapting to the new possible architectures and new types of evaluation. The disadvantages of this approach include the accumulation of errors in the procedures of fuzzification and defuzzification, as well as the fact that there is no reduction in the dimensionality of the feature space. This, in turn, requires calculations of all the rules of fuzzy rules.

In [14], it is proposed to use an adaptive neuro-fuzzy inference system to control the speed of the motor, optimized with the help of collective intelligence. The controller, developed according to fuzzy rules, has an advantage in expert knowledge of the fuzzy inference system and the ability to train neural networks. However, this neuro-fuzzy system implements the learning mechanism only by adjusting the synaptic weights and does not take into account the uncertainty about the state of the object. This type of training leads to the gradual production of erroneous decisions.

The paper [15] presents the results of analytical review and comparison of the most common technologies to support management decisions: hierarchy analysis method, neural networks, fuzzy set theory, genetic algorithms and neuro-fuzzy modeling. The advantages and disadvantages of these approaches are indicated. The spheres of their application are defined. It is shown that the hierarchy analysis method works well under the condition of complete initial information, but due to the need for experts to compare alternatives and choose evaluation criteria has a high degree of subjectivity. The use of fuzzy set theory and neural networks is justified for forecasting problems in conditions of risk and uncertainty. The technology of collective decision-making, which is used both in general elections and in a group of experts, is also considered. It allows reducing the time for conciliation meetings to reach a consensus by pre-analyzing all opinions presented on the plane in the form of points. The consistency of opinions is determined by the distances between them.

In [16], the development of a fuzzy expert system for the diagnosis of cystic fibrosis was carried out. The results showed that the proposed system can be used as a powerful diagnostic tool with an accuracy of $93.02 \%$, a specificity of $89.29 \%$, a sensitivity of $95.24 \%$ and an accuracy of $92.86 \%$ for the diagnosis of cystic fibrosis. However, the proposed fuzzy expert system does not implement the learning mechanism and does not take into account the uncertainty about the state of the object.

In [17], the method of information security risk assessment based on the attack tree model with fuzzy set theory 
and risk probability assessment technology, which is used in the risk scenario of the ship management system, is developed. Fuzzy numbers and expert knowledge are used to determine the factors that affect the probability of a leaf node, and leaf nodes are quantified to obtain the probability of an interval. The disadvantages of the proposed method include the accumulation of error during operation and failure to take into account the uncertainty about the state of the object.

In [18], a fuzzy expert system for early diagnosis of infections in newborns was created. This fuzzy expert system allows the early diagnosis of infections by many indicators. However, this system does not reduce the feature space, which in turn requires significant computing resources of the system.

The paper [19] created a fuzzy expert system with a soft expert set, which allows checking the adequacy of the information provided by the expert and increasing the accuracy of the assessment. However, the disadvantages of this approach include the accumulation of evaluation errors and inability to take into account the uncertainty about the state of the evaluation object. This can lead to inadequate solutions and has great computational complexity.

The analysis showed that the known methods (techniques) [6-19]:

- do not adjust the results taking into account the evaluation error;

- teaching occurs only by adjusting the synaptic weights;

- require significant computing resources;

- do not reduce the dimensionality of the feature space;

- do not take into account uncertainty about the state of the evaluation object;

- are not able to adapt the architecture of the artificial neural network depending on the amount of information coming to the input of the artificial neural network.

Therefore, it is necessary to develop an improved method of finding a solution for neuro-fuzzy expert systems, which is able to effectively search for a solution in conditions of uncertainty, as well as a shortage of computing resources.

\section{The aim and objectives of the research}

The aim of the research is to develop a method for finding a solution for neuro-fuzzy expert systems, which will increase the efficiency of information processing in conditions of uncertainty. To achieve this goal, the following objectives are set:

- to perform a mathematical statement of the problem of analyzing objects and environment;

- to develop the basic procedures and algorithm for the implementation of an improved method of finding solutions for neuro-fuzzy expert systems;

- to test the proposed method and assess its effectiveness.

\section{Mathematical statement of the problem of analyzing objects and environment}

Let's suppose that a vector model is obtained as a result of classifying objects according to their characteristics. The model determines the shape of the studied parameters, so the studied parameters are divided into elementary components according to the characteristics that make up the set $V$ of the elementary components of the analyzed signal. There is also an interpretation of the received signals to a certain structural unit (group).
Data about the object and environment are stored in computer memory in digital form in the form of a matrix $R$ of dimension $(M \times N)$, and has the form [2, 4]:

$$
R=\left\|r_{i, j}\right\|,
$$

where $i=1, \ldots, M ; j=1, \ldots, N$.

Each element of the matrix $R$ is a vector of parameters that characterize each $(i, j)$-th elementary parameter of the signal on some $m$-th $(m=1, \ldots, T)$ set of thematic properties of the structural unit (group):

$$
r_{i, j}=\left(r_{i, j}^{1}, \ldots, r_{i, j}^{T}\right),
$$

the nature of the vector components $r_{i, j}$ in the general case does not play a fundamental role.

Then, with a set of thematic properties $\left\{P_{n}\right\},(n=1, \ldots, K)$, according to which it is necessary to classify the studied signals and threshold values of constraints on the whole set of thematic properties, it is necessary to match the set $P_{n}$ of the $V_{t} \in V,(1 \leq t \leq(M \times N))$ elementary components of the signal that have the $P_{n}$ property for each $P_{n}$ by their threshold constraints.

Then, showing all sorts of options of the feature values within the thresholds of the constraints for each to the $k$-th reference table, we have a matrix of $I^{k l}$ estimates:

$$
\Gamma^{k l}=\left\|q_{u, v}^{k l}\right\|, \quad q_{u, v}^{k l} \in[0,1],
$$

where the answer 1 means that the set of features and their restriction thresholds are used to make a decision about belonging to one of the membership classes and 0 means otherwise, $l$ is the number of options.

However, even with all the advantages of neuro-fuzzy expert systems they unfortunately have certain disadvantages. Here are the main ones [6-9]:

- the accumulation of evaluation error during fuzzification and defuzzification procedures;

- the architecture of the artificial neural network used to form knowledge bases has a rigid architecture, and is not able to adapt during the calculations;

- learning of an artificial neural network is limited only to learning synaptic weights between neurons;

- low productivity of solution search methods even with a small volume of rules;

- great computational complexity of solution search methods;

- large dimension of the feature space.

Therefore, it is necessary to develop a method for finding a solution for neuro-fuzzy expert systems.

5. Development of basic procedures and algorithm for implementing an improved method of finding solutions for neuro-fuzzy expert systems

The Rete method was chosen as the basis for the development of an improved method for finding solutions for neurofuzzy expert systems $[5,10,11]$. The main disadvantage of the Rete method consists in the fact that this method is able to work only with clear products, which does not allow it to be used while processing different types of data.

The algorithm for implementing the proposed search method is shown in Fig. 1. 


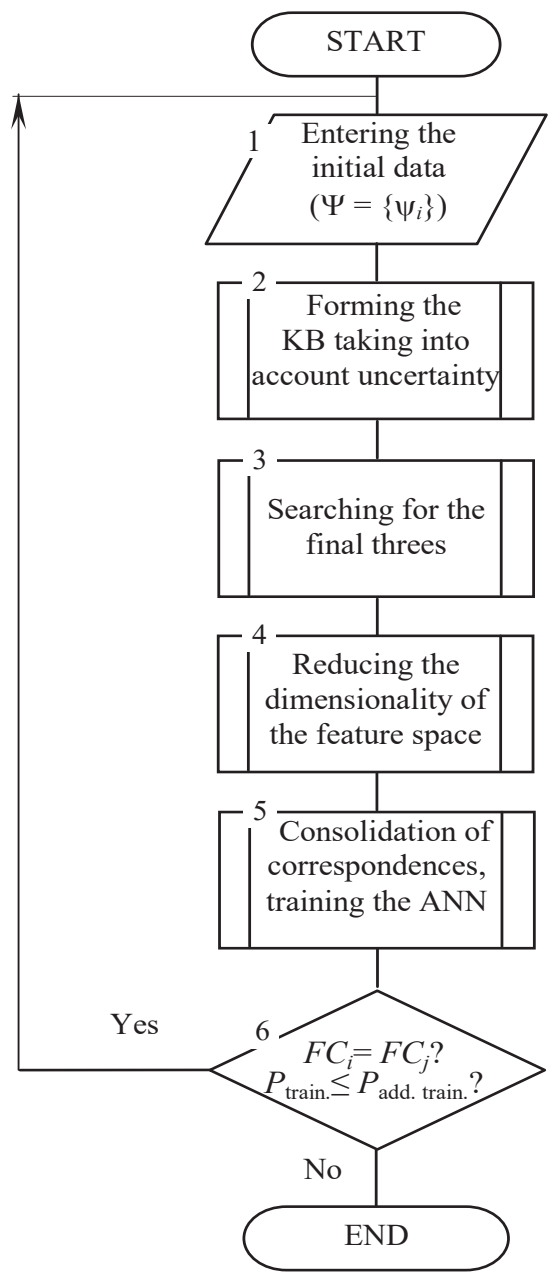

Fig. 1. Algorithm for implementing the proposed method

Step 1. Entering the source data to analyze the object and the environment (step 1 in Fig. 1).

At this stage, the initial data about the object and the environment is entered.

Step 2. Forming a knowledge base (KB) taking into account uncertainty.

At this stage, the KB is formed on the basis of the expressions (4)-(17). While converting values about the object and the environment into fuzzy rules, the value of uncertainty about the radiation sources is taken into account, according to the expressions (10)-(12) [23].

The formal model of the neuro-fuzzy rule base will look like (4):

$$
\left\{P_{n}\right\}=\{\text { Rule }\},
$$

where Rule is a rule of the neuro-fuzzy expert system. Each rule is defined as follows (5):

$$
\text { Rule }=<C \rightarrow S>
$$

where $C$ is the rule condition, $S$ is the consequence of the rule.

Since the model must provide a representation of the grammatical structure of the rules with different types of nested conditions, a recursive mechanism will be used to describe the nodes and end vertices of the rule condition tree. Parameter $C$ is defined as follows (6):

$$
C=<C_{l}, R, C_{r}>
$$

where $C_{l}$ is the left node of the rule condition, $R$ is the relationship between rule nodes, $C_{r}$ is the right node of the rule condition.

Then, we will consider the following parameters.

$$
\begin{aligned}
& C_{l}=F C_{l}\|\operatorname{Null}\| C, \\
& C_{r}=F C_{r}\|\operatorname{Null}\| C,
\end{aligned}
$$

where $F C_{i}$ is the left finite triple of the rule condition, $F C_{r}$ is the right finite triple of the rule condition.

Formulas (7) and (8) allow us to describe conditions with different degrees of nesting.

$$
\begin{aligned}
& F C_{l}=<L, Z, W>, \\
& F C_{r}=<L, Z, W>,
\end{aligned}
$$

where $L$ is the linguistic variable, $Z$ is the condition sign $Z=\{<<>,<=,>=,=, !=\} ; W$ is the value of the condition, which is determined as follows (11).

$$
W=L \| V
$$

where $L$ is the linguistic variable, $V$ is the fixed value (12).

$$
V=T_{i} \| \text { const, }
$$

where $T_{i}$ is the value of a fuzzy variable from the term sets of a linguistic variable, const is the constant. This model allows using not only linguistic variables but also classical variables. In this case, their values can also be compared with constants [5]. $R$ is the set of relations between the nodal vertices $R \subset\left(C_{l} \times C_{r}\right)$ or $R: C_{l} \rightarrow C_{r}$.

We determine the parameter $S$ (a consequence of the rule) similarly to the parameter $C$.

$$
S=<S_{l}, R, S_{r}>
$$

where $S_{l}$ is the left node of the rule consequence, $R$ is the relationship between the nodes of the rule consequence, $S_{r}$ is the right node of the rule consequence.

$$
\begin{aligned}
& S_{l}=F S_{l}\|\operatorname{Null}\| S, \\
& S_{r}=F S_{r}\|\operatorname{Null}\| S,
\end{aligned}
$$

where $F S_{l}$ is the left finite triple of the rule consequence, $F S_{r}$ is the right finite triple of the rule consequence. Formulas (14) and (15) allow us to describe the consequences with different degrees of nesting.

$$
\begin{aligned}
& F S_{l}=<L, \mathrm{Op}, W>, \\
& F S_{r}=<L, \mathrm{Op}, W>,
\end{aligned}
$$

where $L$ is the linguistic variable, Op is the operation, $\mathrm{Op}=\{:=\}, W$ is the consequence value.

Step 3. Searching for finite triples and ANN learning (step 3 on the algorithm diagram).

At this stage of the Rete method, the search for the close finite triples in all the rules of the production knowledge base 
is performed. The matches found between the finite threes are denoted. The rules set out the references of such finite triples to ensure their one-time processing. In contrast to the classical neuro-fuzzy expert systems, in this neuro-fuzzy expert system as an artificial neural network it is proposed to use a neuro-fuzzy evolutionary network, the architecture of which is given in [3,10]. Also, at this stage, training of parameters and architecture of the artificial neural network is performed in accordance with the method of training proposed in [3].

Let's consider the algorithm for finding the correspondences of the finite triples of the decision tree.

Input data: Rule is a database of rules, presented in the form of a decision tree.

Output data: Rule' is a shortened database of the rules represented as a decision tree. Intermediate data: $F C_{i}$ and $F C_{j}$ are the current finite triples.

Step 3. 1. At the beginning of the algorithm, all finite triples are not noted (not checked), $m$ is the number of finite triples. Set the initial value to $i=1$.

Step 3. 2. If $i>m$, then move to step 3. 10.

Step 3. 3. If $F C_{i}$ is noted, then $i=i+1$ and move to step 3. 2.

Step 3. 4. Select $F C_{i}$. Set $j=j+1$.

Step 3. 5. If $j>m$, then note $F C_{i}$ as the finite triple viewed and go to step 3. 2.

Step 3. 6. If $F C_{j}$ is noted, then $j=j+1$ and move to step 3. 5 .

Step 3. 7. Select $F C_{j}$. Follow the procedure of checking the proximity of the end nodes and finite triples $F C_{i}$ and $F C_{j}$.

Step 3. 8. If the result is successful, add $F C_{j}$ to the list of matches for $F C_{i}$, and $F C_{j}$, the finite triple that has been checked.

Step 3. 9. Determination of the learning error. Making a decision on the training of ANN taking into account the type of uncertainty.

Step 3. 10. Move to step 3. 2

Step 3. 11. End.

Step 4. Reducing the dimension of the feature space (step 4 in Fig. 1)

The proposed procedure for aggregating features works as follows. Initially, based on the initial set of characteristics of the considered objects, the initial characteristics are combined into groups of criteria with verbal ordinal scales with a small number of gradations (3)-(5).

The criteria should have such scales of assessments, which, on the one hand, will reflect the aggregate qualities of objects, and on the other hand, will be clear during the final selection of the object or their classification.

Formally, the problem of reducing the dimensionality of the feature space is as follows:

$$
X_{1} \times \ldots \times X_{m} \rightarrow Y_{1} \times \ldots \times Y_{n}, \quad n<m,
$$

where $X_{1}, \ldots, X_{m}$ is the original set of features, $Y_{1}, \ldots, Y_{n}$ is the new set of features, $m$ is the dimension of the original feature space, $n$ is the dimension of the new feature space. Each of the features has its own scale $X_{i}=\left\{x_{i}^{1}, \ldots, x_{i}^{g_{i}}\right\}, i=1, \ldots, m, Y_{i}=\left\{y_{i}^{1}, \ldots, y_{i}^{h_{i}}\right\}$, $j=1, \ldots, n$, with an ordered gradation of estimates.

All gradations of marks on the feature scales act as objects of classification. Grades of solutions of the $i$-th level are gradations of estimations on a scale of the criterion. In the classification block of the $(i+1)$-th level of hierarchy, there are the criteria of the $i$-th level. Criteria are considered to be features, the set of gradations of evaluations of which are new objects of classification in the reduced feature space, and the classes of solutions will now be gradations of evaluations on the scale of the compiled criterion of the $(i+1)$-th level.
The procedure is repeated until there is a single compiled upper-level criterion, the scale of which forms the necessary ordered classes of solutions $C_{1}, \ldots, C_{q}$.

Thus, a one-to-one correspondence between the classes of solutions $C_{1}, \ldots, C_{q}$ and the set of initial indicators - the set $X_{1} \times \ldots \times X_{m}$ of all possible combinations of gradations of estimates on the scales of the criteria $X_{i}=\left\{x_{i}^{1}, \ldots, x_{i}^{g_{i}}\right\}, i=1, \ldots, m$, $K_{1}, \ldots, K_{m}$ is established and the boundaries of classes are found, which allows constructing a classification of real alternatives $A_{1}, \ldots, A_{p}$, evaluated by many criteria.

Step 5. Consolidation of correspondences and ANN training (step 5 on the algorithm diagram).

At this stage, a recursive procedure is performed to check the proximity of intermediate nodes of decision trees. This procedure provides aggregation of correspondences between conditions in the rules of the knowledge base. Also, at this stage, training of the ANN architecture and parameters is performed.

Then, we should consider the algorithm for finding the aggregation of the found matches.

Input data: Rule' is a shortened rule base, presented in the form of a decision tree, with combined identical finite triples; $S_{p}$ is the list of finite triples for which matches are found; $k$ is the number of items in the list $S_{p} . S_{p i}$ is the list of the finite triple $F C_{i}$, containing the corresponding finite triples with indices; $k_{i}$ is the number of items in the list $S_{p i}$.

Output data: Rule" is a shortened rule base, which combines all identical conditions.

Intermediate data: $F C_{i}$ and $F C_{j}$ are the current finite triples, $C_{i}$ and $C_{j}$ are the parent nodes for $F C_{i}$ and $F C_{j}$.

Step 5. 1. Set $i=1$.

Step 5. 2. Choose $F C_{i}$ in the decision tree, which is on the $i$-th place in the list $S_{p}$.

Step 5.3. Set $j=1$.

Step 5.4. Select the finite triple $F C_{j}$ from the list $S_{p i}$, which is in the $j$-th place. Delete parent nodes $C_{i}$ and $C_{j}$ for $F C_{i}$ and $F C_{j}$.

Step 5. 5. Perform a recursive procedure to check intermediate nodes $C_{i}$ and $C_{j}$.

Step 5.6. If the result of the function is successful, match the nodes $C_{i}$ and $C_{j}$, otherwise move to step 5. 7 .

Step 5. 7. $J=j+1$. If $j>k$, move to step 5. 8, otherwise move to step 5.4.

Step 5.8. $I=i+1$. If $i>k$, move to step 5. 10, otherwise move to step 5. 2 .

Step 5.9. Determination of a learning error. Making a decision on the training of ANN taking into account the type of uncertainty.

Step 5. 10. End.

Step 6. Checking the proximity assessment metric and determining the ANN learning error (step 6 in Fig. 1).

At this stage, the metrics of the proximity of the obtained solutions and the learning error are determined in order to make management decisions.

\section{Testing and evaluation of the effectiveness of the proposed solution search method}

Modeling of the proposed method was performed in the MathCad 2014 software environment (USA).

To evaluate the effectiveness of the proposed method, modeling was performed using the following components:

- personal computer with installed special software and MathCad 2014; 
- Agilent OmniBER 718 digital flow analyzer (USA) with software and a set of connecting cables that measures parameters;

- TRC 274 H/V/UHF Jammer (20-3,000 MHz) jammer (France), which simulated the operation of the electronic warfare system (transmitter power - $20 \mathrm{~W}$. Suppressive frequency band - $10 \mathrm{MHz}$, interference type - noise barrier interference with frequency manipulation; the strategy of the EW complex - dynamic);

- MikroTik NetMetal 5 broadband radio access stations (Latvia) with the following parameters (128 positional quadrature amplitude manipulation; radiation bandwidth $40 \mathrm{MHz}$, radiation power $1 \mathrm{~W}$; radiation frequency $2.1-3 \mathrm{GHz})$.

The following linguistic variables were used to solve this problem:

1. The bit error probability (BER): Range of admissible values: $10^{-3} \div 10^{-12}$; $\mathrm{BER}=\ll$ Bit error probability $»=\{\ll$ channel is unusable», «channel is partly unusable», «channel is operational»\}.

2. The channel overlap factor: Range of admissible values: $0 \div 1 ; \mathrm{KOV}=\ll$ Channel overlap factor $»=\{\ll$ channel is completely blocked by interference», «channel is partially blocked by interference», «channel without interference»\}.

3. The noise transmitter power: Range of admissible values: $1 \div 20 \mathrm{~W}$; PJ $=\ll$ Interference transmitter power $=\{\ll l o w$ power», «medium power», «high power»\}.

4. The frequency of radiation of the interference transmitter: Range of admissible values: $20 \div 3,000 \mathrm{MHz}$.

$\mathrm{FJ}=\ll$ Interference transmitter frequency»=\{«Lower frequency band», «middle frequency band», «upper frequency band»\}.

5. The power of the broadband radio access station: Range of admissible values: $0 \div 1 \mathrm{~W}$.

$\mathrm{PW}=\ll$ Broadband radio access station power $\gg=\{\ll$ low power», «medium power», «high power»\}.

6 . The type of signal-code design of the broadband radio access station: Range of admissible values: $4 \div 128$ positional quadrature amplitude manipulation; $\mathrm{SC}=\ll$ Type of signalcode design of the broadband radio access station $»=\{\ll$ low position», «medium position», «high position»\}.

7. The frequency of radiation of the broadband radio access station: Range of admissible values: 2,100 $\div 3,000 \mathrm{MHz}$; $\mathrm{FW}=\ll$ Broadband radio station radiation frequency»= $=\{\ll$ Lower band», «middle band», «upper band» $\}$.

8. The uncertainty of the radio-electronic environment: Range of admissible values: complete uncertainty $\div$ complete knowledge; $\mathrm{UN}=\ll$ Uncertainty of the radio-electronic environment» $=\{\ll$ Complete uncertainty», «partial uncertainty», «complete knowledge»\}.

To simplify further writing, we will denote the fuzzy variables «zero» - «Z», «low» - «L», «normal» - «N», «high» $-\ll H »$.

The expert (operator of the broadband radio access station) performed the initial adjustment of the membership functions of the terms of the set of the neuron-fuzzy expert system, because all sources of radio radiation have different characteristics. The expert indicated which primary values and calculated parameters should be considered high for a given broadband radio access station, which are average and which are low. The membership functions for the analysis of the radio-electronic environment are presented in the specified form according to the formula:

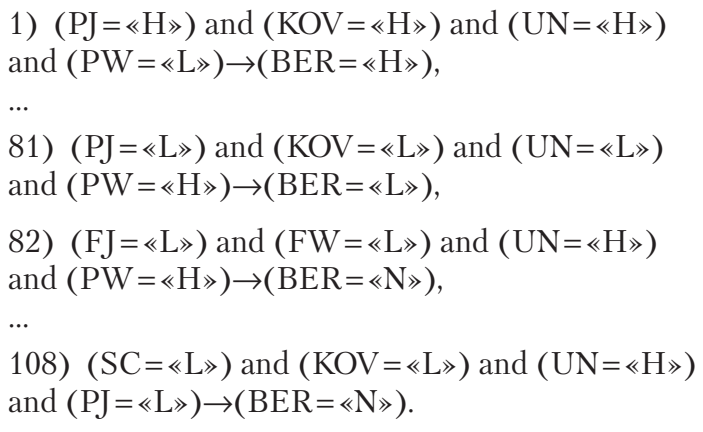

This example provides part of the rule base of the neural fuzzy expert system. In the main rule database, there are the rules not only with connections of conditions using T-norms, but also using T-conorms and with negations of conditions.

In the worst case, to find a solution, the system should check all the rules contained in the rule database. That is, you need to check 405 conditions and calculate 297 T-norm operations. This is an unacceptably long process, given the limitations of the hardware.

The input data for the neuro-fuzzy expert system are the transmitter power indicators of the broadband access station. The indicators are as follows: the type of signal-code design of the broadband radio access station, REE uncertainty (the proportion of parameters known about the jammer), the frequency of radiation of the broadband radio access station. After passing the fuzzification stage, the system received fuzzy estimates for each controlled parameter.

For example, if the value of the bit error probability in the channel is $\mathrm{BER}=10^{-3}$, then:

- the power of the broadband radio access station is maximum and equal to $1 \mathrm{~W}$;

- the 4-position quadrature amplitude manipulation is used;

- the REE uncertainty is full;

- the radiation frequency of the broadband radio access station is lower and these values are fuzzified for this station as «low».

The rule from the knowledge base will be executed:

«The bit error probability is high, the position of the signal-code design is low, the REE uncertainty is high, the power of the jammer transmitter is high, the overlap coefficient of the channel spectrum is full; then the jammer and the broadband access station operate on the same frequency».

Therefore, it is necessary to adjust the radiation frequency of the broadband radio access station $=\ll$ high $\gg$. Then, the «high» value of the linguistic variable «radiation frequency of the broadband radio access station» was defuzzified, and a new value of the radiation frequency to be set was transmitted to the broadband radio access station.

We will evaluate the complexity $\Xi_{\bmod \text { Rete }}(n, m, k, t, s)$ of finding a solutionn for a neuro-fuzzy expert system operating on the basis of a modified Rete method. It is necessary to first form an estimate of the complexity of the neuro-fuzzy expert system with the classical method of finding a solution and then estimate the reduction $\Xi_{\text {Rete }}(n, m)$ in the number of calculations.

Let $n$ be the number of rules in the neuro-fuzzy expert system, where $m_{i}$ is the number of conditions in the $i$-th rule $(i=1, \ldots, n) ; k$ is the number of different linguistic variables involved in the rule conditions; $t_{i}$ is the power of the term set of the $i$-th linguistic variable involved in the rule conditions; $s$ is the number of relationships between variables in the conditions. 
It should be noted that the modified Rete method reduces the number of iterations while searching for a solution and reduces the number of calculations at each iteration.

In this case, the average complexity of one cycle of checking the rules in the operation of a neuro-fuzzy expert system with the classical method will look like (19):

$$
\begin{aligned}
& \Xi_{\text {Rete }}(n, m)=\sum_{i=1}^{n}\left(2 \times m_{i}-1\right), \\
& \Xi_{\text {mod Rete }}(n, m, k, t, s)= \\
& =\sum_{i=1}^{n}\left(m_{i}-1\right)+\min \left\{\sum_{i=1}^{n}\left(m_{i}\right), \sum_{i=1}^{k}\left(t_{i}\right) \times s\right\},
\end{aligned}
$$

where the complexity of processing the $t$-norms or $t$-conorms is first calculated, and then the minimum value of the complexity of all conditions of rules and complexity of all combinations of elements of term-sets of variables and signs of relations is calculated.

Estimates of complexity for rule bases (RB) are given in Table 1.

To compare the efficiency of assessment, the classical Rete, Treat and Leaps methods and the proposed method were used [20-22].

This table clearly shows that the use of the modified Rete method is justified for rule databases that contain a large number of rules and a relatively small number of linguistic variables. In this case, the modified Rete method allows us to speed up information processing almost twice in comparison with the fuzzy expert system, and by $20-25 \%$ in comparison with the classical Rete method.

Table 1

Values of complexity estimates

\begin{tabular}{|c|c|c|c|c|c|c|c|c|c|c|}
\hline & $n$ & $M_{\text {mid }}$ & $k$ & $T_{\text {mid }}$ & $s$ & $\Xi_{\text {NES }}$ & $\Xi_{\text {Rete }}$ & $\Xi_{\text {Treat }}$ & $\Xi_{\text {Leaps }}$ & $\Xi_{\text {mod Rete }}$ \\
\hline RB 1 & 20 & 9 & 12 & 5 & 6 & 150 & 150 & 150 & 150 & 150 \\
\hline RB 2 & 200 & 9 & 12 & 5 & 6 & 1,500 & 1,420 & 1,550 & 1,580 & 1,140 \\
\hline RB 3 & 400 & 9 & 12 & 5 & 6 & 3,450 & 3,300 & 3,500 & 3,550 & 2,660 \\
\hline RB 4 & 600 & 9 & 12 & 5 & 6 & 7,000 & 6,560 & 6,600 & 6,690 & 5,050 \\
\hline RB 5 & 20 & 9 & 12 & 5 & 6 & 150 & 150 & 150 & 150 & 150 \\
\hline RB 6 & 200 & 9 & 12 & 5 & 6 & 1,500 & 1,420 & 1,550 & 1,580 & 1,140 \\
\hline RB 7 & 400 & 9 & 12 & 5 & 6 & 3,450 & 3,300 & 3,500 & 3,550 & 2,660 \\
\hline RB 8 & 600 & 9 & 12 & 5 & 6 & 7,000 & 6,560 & 6,600 & 6,690 & 5,050 \\
\hline RB 9 & 20 & 9 & 12 & 5 & 6 & 150 & 150 & 150 & 150 & 150 \\
\hline RB 10 & 200 & 9 & 12 & 5 & 6 & 1,500 & 1,420 & 1,550 & 1,580 & 1,140 \\
\hline RB 11 & 400 & 9 & 12 & 5 & 6 & 3,450 & 3,300 & 3,500 & 3,550 & 2,660 \\
\hline RB 12 & 600 & 9 & 12 & 5 & 6 & 7,000 & 6,560 & 6,600 & 6,690 & 5,050 \\
\hline RB 13 & 20 & 9 & 12 & 5 & 6 & 150 & 150 & 150 & 150 & 150 \\
\hline RB 14 & 200 & 9 & 12 & 5 & 6 & 1,500 & 1,420 & 1,550 & 1,580 & 1,140 \\
\hline RB 15 & 400 & 9 & 12 & 5 & 6 & 3,450 & 3,300 & 3,500 & 3,550 & 2,660 \\
\hline RB 15 & 600 & 9 & 12 & 5 & 6 & 7,000 & 6,560 & 6,600 & 6,690 & 5,050 \\
\hline
\end{tabular}

The results of evaluating the state of the radio-electronic environment for different systems are presented in Fig. 2.

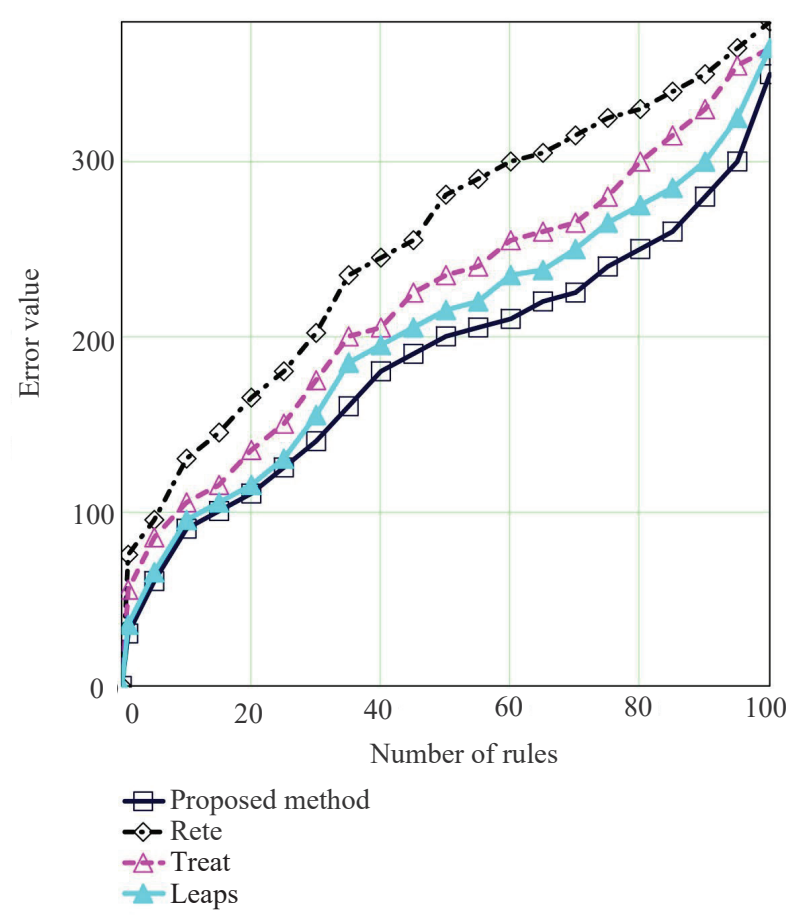

Fig. 2. Comparison of the efficiency of the obtained assessment for different methods

\section{Discussion of the results on the development of the improved solution search method}

The research of the developed method showed that this method provides on average $20-25 \%$ higher efficiency of assessment and does not accumulate errors during training (Table 1). The researches were performed under the limitations outlined in section 5 of this reseach.

This is explained by the use of evolving artificial neural networks, advanced training procedures for artificial neural networks, one-time calculation of the same conditions while finding solutions and the use of references to the same rules.

The features of information analysis systems are:

- a large number of analyzed parameters; dynamic change of the situation;

- functioning in conditions of uncertainty about the state of the situation;

- constant updating of the signal base;

- functioning in the conditions of influence of natural and intentional disturbances.

However, in the conditions of constant replenishment of knowledge bases, the use of the classical Rete method is unacceptable in terms of adequacy and correctness of calculations.

The main advantages of the proposed evaluation method are:

- does not accumulate learning errors during the search for solutions by training artificial neural networks (adjusting the parameters and architecture of the artificial neural network);

- lower computational complexity, Table 1 (20-25\% increase in decision-making efficiency);

- while searching for a solution, the same conditions are calculated only once, which provides acceleration of the rules revision cycle;

- less memory usage, because it uses references to rules instead of the same rules; 
- allows defining not only separate identical conditions in the rule database, but also blocks of identical conditions that allows increasing the speed of decision making;

- allows reducing the feature space in the analysis by using the feature space reduction procedure;

- allows working with clear and fuzzy products;

- takes into account the type of uncertainty about the state of the radio-electronic environment.

The disadvantages of the proposed method include:

- loss of informativeness in the assessment due to the construction of the membership function. This loss of information can be reduced by choosing the type of membership function and its parameters in the practical implementation of the proposed method in decision support systems. The choice of the type of membership function depends on the computing resources of a particular electronic computing device.

- lower accuracy of assessment on a single parameter of condition assessment;

- loss of accuracy of the results during the reconstruction of the architecture of the artificial neural network.

This research is a further development of research conducted by the authors, aimed at developing the theoretical foundations for improving the efficiency of artificial intelligence systems, which was published earlier [1-3].

As for the limitations of this method, this method is adapted for the analysis of objects and the environment, in conditions of its uncertainty and high dynamics. However, the proposed method is able to successfully solve the problem of data analysis with appropriate adaptation to a particular type of decision support systems.

However, as it was already mentioned, the known methods accumulate errors, that is why the proposed method suggests the use of evolving artificial neural networks. The results of efficiency evaluation are shown in Fig. 3.

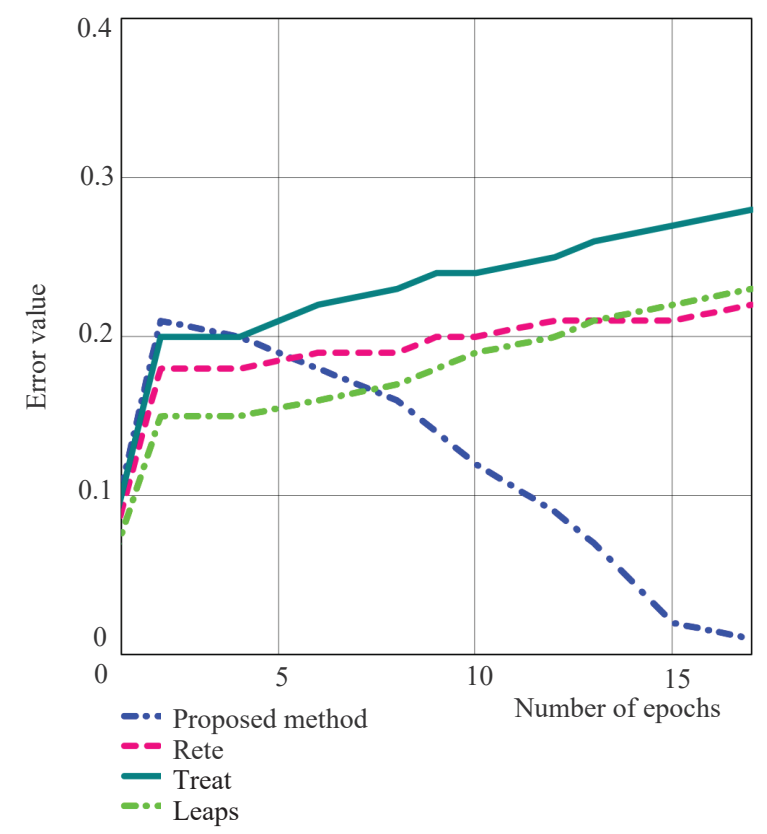

Fig. 3. Evaluation of the effectiveness of evolving artificial neural networks

Fig. 3 shows that the use of evolving artificial neural networks allows not to accumulate learning errors after the 3 -rd epoch and there is a gradual reduction of learning errors.
Let's consider the cost of training an evolving artificial neural network.

A training sample containing data on the radiation source was used for modeling. The rule base from this sample was used for modeling.

Rete, Treat and Leaps and the proposed methods were used to compare the cost of ANN training.

The results of the comparison for different methods are presented in Table 2.

Table 2

Comparison of the results for different methods

\begin{tabular}{|c|c|c|c|c|}
\hline System & $\begin{array}{c}\text { Num- } \\
\text { ber of } \\
\text { parame- } \\
\text { ters }\end{array}$ & $\begin{array}{c}\text { Number of } \\
\text { calculated } \\
\text { rule condi- } \\
\text { tions }\end{array}$ & $\begin{array}{c}\text { Number } \\
\text { of rules } \\
\text { in the } \\
\text { database }\end{array}$ & Time, $\mathrm{s}$ \\
\hline Rete & 8 & 350 & 100 & 0.1398 \\
\hline Treat & 8 & 350 & 100 & 0.1501 \\
\hline Leaps & 8 & 350 & 100 & 0.1456 \\
\hline $\begin{array}{c}\text { Proposed method } \\
\text { with evolving ANN }\end{array}$ & 8 & 387 & 100 & 0.954 \\
\hline
\end{tabular}

As it can be seen from Table 2, for the ANN training, it is necessary to calculate additional 37 rules (training sample), which is $10.5 \%$, which increases the computational complexity of training an artificial neural network, but gives a gain in efficiency of 20-25\% compared to the classical Rete method.

Areas of further research should be aimed at reducing computational costs in the processing of various types of data in special-purpose systems. At the same time, in the further development of the specified research there may be problems with increasing the efficiency of artificial neural networks. This is due to the use of only classical membership functions in this study. So, it is necessary to build membership functions with a non-classical form and add the procedure for constructing a membership function to the method.

\section{Conclusions}

1. A mathematical statement of the problem of analyzing objects and environment is carried out, which proved the possibility of the following:

- to identify the features and thereby to reduce the subjectivity of future results at this stage of the research;

- to carry out statistical processing of a large amount of information in the shortest possible time due to automation of its processing;

- to repeat the calculation many times in different input situations.

2. The basic procedures and algorithms for implementing an improved method of finding solutions for neuro-fuzzy expert systems are developed.

The proposed method differs from the known ones. The type of uncertainty is additionally taken into account while assessing the radio-electronic situation, namely: full awareness, complete uncertainty, partial uncertainty, «hopeless» uncertainty. Taking into account the type of uncertainty leads to changes in the parameters of the decision-making process, which can be explained by a number of factors:

- changes in the initial data on the basis of which decisions are made about the collection, storage, processing and transfer of information concerning the condition of analysis object; 
- changes in the external conditions and current requirements (quality criteria) for the collection, storage, processing and transmission of information on the state of the object;

- changes in methods and means of decision-making on the collection, storage, processing and transmission of information on the state of the object;

- to increase the efficiency of information processing, evolving artificial neural networks are used, with an algorithm for their training, which occurs by training their architecture, synaptic scales, type and parameters of the membership function;

- the ability to work both with clear and fuzzy products through the use of evolving artificial neural networks;

- the ability to reduce the feature space by applying the feature space reduction procedure;

- no accumulation of learning errors of artificial neural networks as a result of processing the information arriving to the input of artificial neural networks by training the architecture and parameters.

3. The evaluation of the efficiency of the proposed method is carried out. This example showed an increase in the effi- ciency of evaluation at the level of $20-25 \%$ by the efficiency of information processing.

\section{Acknowledgments}

The authors' team expresses its gratitude for the assistance:

To the doctor of technical sciences, professor Oleksiy Viktorovych Kuvshinov - deputy head of the educational and scientific institute of the Ivan Chernyakhovsky national defense university of Ukraine.

To the doctor of technical sciences, senior researcher Yuriy Volodymyrovych Zhuravskiy - leading researcher at the research center of the Zhytomyr military institute named after S. P. Korolyov.

To the candidate of technical sciences, associate professor Oleksandr Mykolayovych Bashkirov - leading researcher at the central research institute of armaments and military equipment of the Armed Forces of Ukraine.

\section{References}

1. Bashkirov, O. M., Kostina, O. M., Shishats'kiy, A. V. (2015). Development of integrated communication systems and data transfer for the needs of the Armed Forces. Weapons and military equipment, 5 (1), 35-39.

2. Trotsenko, R. V., Bolotov, M. V. (2014). Data extraction process for heterogeneous sources. Privolzhskiy nauchnyi vestnik, 12-1 (40), 52-54.

3. Bodyanskiy, E., Strukov, V., Uzlov, D. (2017). Generalized metrics in the problem of analysis of multidimensional data with different scales. Zbirnyk naukovykh prats Kharkivskoho universytetu Povitrianykh Syl, 3, 98-101.

4. Semenov, V. V., Lebedev, I. S. (2019). Processing of signal information in problems of monitoring information security of unmanned autonomous objects. Scientific and Technical Journal of Information Technologies, Mechanics and Optics, 19 (3), $492-498$. doi: https://doi.org/10.17586/2226-1494-2019-19-3-492-498

5. Zhou, S., Yin, Z., Wu, Z., Chen, Y., Zhao, N., Yang, Z. (2019). A robust modulation classification method using convolutional neural networks. EURASIP Journal on Advances in Signal Processing, 2019 (1). doi: https://doi.org/10.1186/s13634-019-0616-6

6. Zhang, D., Ding, W., Zhang, B., Xie, C., Li, H., Liu, C., Han, J. (2018). Automatic Modulation Classification Based on Deep Learning for Unmanned Aerial Vehicles. Sensors, 18 (3), 924. doi: https://doi.org/10.3390/s18030924

7. Kalantaievska, S., Pievtsov, H., Kuvshynov, O., Shyshatskyi, A., Yarosh, S., Gatsenko, S. et. al. (2018). Method of integral estimation of channel state in the multiantenna radio communication systems. Eastern-European Journal of Enterprise Technologies, 5 (9 (95)), 60-76. doi: https://doi.org/10.15587/1729-4061.2018.144085

8. Belousov, S. M. (2006). Matematicheskaya model' mnogopotochnoy sistemy massovogo obsluzhivaniya, upravlyaemoy planirovshchikom resursov. Vestnik Novosibirskogo gosudarstvennogo universiteta. Ser.: Informatsionnye tehnologii, 4 (1), 14-26.

9. Kuchuk, N., Mohammed, A. S., Shyshatskyi, A., Nalapko, O. (2019). The method of improving the efficiency of routes selection in networks of connection with the possibility of self-organization. International Journal of Advanced Trends in Computer Science and Engineering, 8 (1.2), 1-6. Available at: http://www.warse.org/IJATCSE/static/pdf/file/ijatcse01812sl2019.pdf

10. Gerami Seresht, N., Fayek, A. R. (2020). Neuro-fuzzy system dynamics technique for modeling construction systems. Applied Soft Computing, 93, 106400. doi: https://doi.org/10.1016/j.asoc.2020.106400

11. Folorunso, O., Mustapha, O. A. (2015). A fuzzy expert system to Trust-Based Access Control in crowdsourcing environments. Applied Computing and Informatics, 11 (2), 116-129. doi: https://doi.org/10.1016/j.aci.2014.07.001

12. Luy, M., Ates, V., Barisci, N., Polat, H., Cam, E. (2018). Short-Term Fuzzy Load Forecasting Model Using Genetic-Fuzzy and Ant Colony-Fuzzy Knowledge Base Optimization. Applied Sciences, 8 (6), 864. doi: https://doi.org/10.3390/app8060864

13. Salmi, K., Magrez, H., Ziyyat, A. (2019). A Novel Expert Evaluation Methodology Based on Fuzzy Logic. International Journal of Emerging Technologies in Learning (iJET), 14 (11), 160. doi: https://doi.org/10.3991/ijet.v14i11.10280

14. Allaoua, B., Laoufi, A., Gasbaoui, B., Abderrahmani, A. (2009). Neuro-Fuzzy DC Motor Speed Control Using Particle Swarm Optimization. Leonardo Electronic Journal of Practices and Technologies, 15, 1-18. Available at: http://lejpt.academicdirect.org/ A15/001_018.pdf

15. Rybak, V. A., Shokr, A. (2016). Analysis and comparison of existing decision support technology. System analysis and applied information science, $3,12-18$. 
16. Hassanzad, M., Orooji, A., Valinejadi, A., Velayati, A. (2017). A fuzzy rule-based expert system for diagnosing cystic fibrosis. Electronic Physician, 9 (12), 5974-5984. doi: https://doi.org/10.19082/5974

17. Shang, W., Gong, T., Chen, C., Hou, J., Zeng, P. (2019). Information Security Risk Assessment Method for Ship Control System Based on Fuzzy Sets and Attack Trees. Security and Communication Networks, 2019, 1-11. doi: https://doi.org/10.1155/2019/3574675

18. Safdari, R., Kadivar, M., Nazari, M., Mohammadi, M. (2017). Fuzzy Expert System to Diagnose Neonatal Peripherally Inserted Central Catheters Infection. Health Information Management, 13 (7). pp. 446-452.

19. Al-Qudah, Y., Hassan, M., Hassan, N. (2019). Fuzzy Parameterized Complex Multi-Fuzzy Soft Expert Set Theory and Its Application in Decision-Making. Symmetry, 11 (3), 358. doi: https://doi.org/10.3390/sym11030358

20. Mikhailov, I. S., Zaw, M. (2015). Finding sloutions by the modified Rete algorithm for fuzzy expert systems. Software \& Systems, 4, 142-147. doi: https://doi.org/10.15827/0236-235X.112.142-147

21. Mazhara, O. O. (2014). Comparison of TREAT and RETE pattern matching algorithms. Adaptyvni systemy avtomatychnoho upravlinnia, 1 (24), 53-61.

22. Mazhara, O. A. (2015). Treat algorithm implementation by the basic match algorithm based on CLIPS programming environment. Electronic Modeling, 37 (5), 61-75.

23. Koshlan, A., Salnikova, O., Chekhovska, M., Zhyvotovskyi, R., Prokopenko, Y., Hurskyi, T. et. al. (2019). Development of an algorithm for complex processing of geospatial data in the special-purpose geoinformation system in conditions of diversity and uncertainty of data. Eastern-European Journal of Enterprise Technologies, 5 (9 (101)), 35-45. doi: https://doi.org/10.15587/ 1729-4061.2019.180197

24. Dudnyk, V., Sinenko, Y., Matsyk, M., Demchenko, Y., Zhyvotovskyi, R., Repilo, I. et. al. (2020). Development of a method for training artificial neural networks for intelligent decision support systems. Eastern-European Journal of Enterprise Technologies, 3 (2 (105)), 37-47. doi: https://doi.org/10.15587/1729-4061.2020.203301 